\title{
Instruction on rhythmic structure during learning enhances the breaststroke kick efficiency
}

\begin{tabular}{|c|c|}
\hline $\begin{array}{r}\text { Bettina RIED* } \\
\text { Graciele Massoli RODRIGUES } \text { / }^{* * *} \\
\text { Cassio de Miranda MEIRA JUNIOR }{ }^{* * * *}\end{array}$ & $\begin{array}{l}\text { *Escola Superior de } \\
\text { Educação Física de } \\
\text { Jundiaí, Jundiaí, SP, } \\
\text { Brasil. } \\
{ }^{* *} \text { Universidade São } \\
\text { Judas Tadeu, São } \\
\text { Paulo, SP, Brasil. } \\
\text { *** Escola de } \\
\text { Artes, Ciências } \\
\text { e Humanidades, } \\
\text { Universidade de São } \\
\text { Paulo, São Paulo, SP, } \\
\text { Brasil. }\end{array}$ \\
\hline
\end{tabular}

Abstract

Motor learning can be fostered by visual or auditory instruction conveying information on different features of the skill, like spatial and rhythmic characteristics. For swimming skills like the breaststroke kick, manuals predominantly emphasise spatial features, neglecting rhythmic aspects - even though motor learning considers movement rhythm crucial for distinguishing one skill from another. We aimed to analyse the impact of instruction containing or not the adequate rhythmic pattern information, conveyed by visual or auditory stimulus, on learning the breaststroke kick. Fifty university students, assigned to four experimental groups (auditory, visual, with and without rhythmic information), performed 400 acquisition plus 50 retention and 50 transfer trials during which stroke index, rhythmic and spatial pattern indices and instruction request frequency were mapped. Results showed a marginal difference $(p=.075)$ between higher indices in the retention test of participants receiving information about adequate rhythm, as well as a strong correlation between stroke index and rhythm pattern index, but not with spatial pattern index. No difference between auditory and visual groups was found. This result supports earlier research on the impact of rhythmic information on the learning of complex motor skills, and emphasises the role rhythm plays in skill efficiency and consequently in motor learning.

KEYWORDS: Instruction; Performance; Motor learning; Swimming; Breaststroke.

\section{Introduction}

Several factors contribute to learning of motor skills, especially in sports, to enhance acquisition and performance. Once aware of the aim to be attained, the learner seeks the best possible way to accomplish the aim by successive trials, processing information from internal (proprioceptive) and external sources (previous information, environmental reactions and augmented feedback), whose interference in the learning process may vary according to several factors ${ }^{1}$.

Information about the motor pattern itself may be made available through visual or auditory information ${ }^{2}$, whose impact on the learning process varies according to the sort of skill to be learned, the learner's level of expertise and previous experience, besides other factors $^{3,4}$. In certain situations visual instruction will be more beneficial, in others, auditory, and in others, a combination of both, for example when directing the learner's attention to crucial features in the skill shown ${ }^{3,5}$. One of these features is the rhythmic structure of the skill, which is a distinctive characteristic of a skill and essential for the learner to generate a motor program $^{6-8}$. Movement rhythm is considered one of the profound invariant structural features of a skill, and will be kept stable even if parameters like total movement time or force application have to be changed due to environmental or other constraints' ${ }^{9}$. Its contribution 
to movement outcome increases as the interaction between components of the movement becomes more complex ${ }^{7}$. Furthermore, attaining a stable rhythm has been identified as an important criterion to assess the success of motor learning, given its importance as a condition for optimal performance of a motor skill which should be one of the primary aims in motor learning, especially in early learning phases ${ }^{7}$.

Given that the rhythmic structure is essential, it should be made available to the learner in the most comprehensible way possible, which not necessarily has to be auditory: rhythmic structures can be perceived also via visual or tactile pathways ${ }^{10,11}$ such as images, both static and dynamic. Showing a skill to a learner therefore also conveys information about its rhythmic structure. Since auditory and visual pathways are most frequently used for conveying information in motor skill teaching settings, and their efficiency is specific regarding task complexity, learner's experience, besides other situational constraints ${ }^{3,4}$, we decided to compare these two pathways in order to determine whether they convey the information about the rhythmic structure of the breaststroke kick equally well.

Rhythmic structure is defined as "explicit divisions of time or space into intervallic time systems, recurrent and often (but not always) characterized by periodicity" 12 . This definition implies that a certain skill's rhythmic structure is twofold: on one hand, the relative timing depicts the duration of each component within the whole skill; on the other, the typical sequence of stresses and non-accented phases governs muscular tension and relaxation phases. Optimization of both features is crucial to reduce energy cost, for example in skills like rowing, in which a relatively longer relaxation phase will imply better energy balance, but affect speed. If the tension phase was extended beyond the ideal relative timing, speed would increase but energy use would no longer be optimal ${ }^{7}$.

In some skills it is especially critical to keep the appropriate movement rhythm: in swimming skills, propulsion is generated by "transmitting momentum from the propelling parts of the body on the water, producing a counter bearing" ${ }^{13}$, which is a portion of water with higher density against which the swimmer braces himself in order to propel himself forward. Both creating and exploiting of these denser portions of water are crucial for generating propulsion, and they can only be exploited to their maximum when actions oscillate harmonically, in regular spatial and temporal patterns, in accordance with the typical patterns of the skill to be performed ${ }^{14}$. Water is an unstable environment, in which regions with higher density will only last for short times, and therefore the patterns of timing and force of propulsive movements have to be perfectly coordinated in order to be effective: as shown by both TAKAGI et al. ${ }^{15}$ and Seifert and Chollet ${ }^{16}$, temporal coordination in swimming skills is directly related to performance.

Incongruously, instructions mostly emphasize spatial patterns, passing over rhythmic patterns. Most swimming manuals show detailed descriptions of stroke techniques, but their descriptions are limited to spatial features of the stroke and touch upon their rhythmic features only in passing. MAKARENKO ${ }^{17}$ is the only author to do the opposite: his description of the breaststroke kick focuses on rhythmic features, dedicating less than one third of his kick description to spatial features. Other renowned authors such as Lewin $^{18}$, Counsilman ${ }^{19}$, Reischle ${ }^{20}$, Maglischo ${ }^{21}$, Colwin $^{22}$, Ungerechts, Volck, Freitag ${ }^{23}$, Bissig et al. ${ }^{24}$, and WiLKe ${ }^{25}$ describe the spatial pattern in detail, reinforcing their focus on spatial features by illustrations that show exact angles of flexion and extension of all limbs involved in the skill. Their only mention of rhythm is a passing note remarking that the insweep phase has to be "explosive", without mentioning other rhythmic features of the skill. This omission is remarkable considering that, if the rhythmic pattern was inverted, i.e. if acceleration and force application occurred in the knee flexion phase instead of the knee extension phase, propulsion would be generated in the opposite direction (backwards).

Considering that motor learning theory stresses the importance of rhythm patterns for successful skill learning, we hypothesize that there exists a very close relation between providing information about the appropriate rhythmic structure of a skill and the learning outcome. In other words, if the learner is provided clear information about the rhythmic structure of the skill, the learning process will result in a better outcome than without this information. On the other hand, if the information provided about rhythmic structure were misleading, learning outcome would suffer.

To test this hypothesis, we analysed the impact of instruction containing or not information about the skill's adequate rhythmic pattern, conveyed by visual or auditory stimulus, on learning the breaststroke kick. A common way to assess swimming stroke learning, is to measure the achieved efficiency via the stroke index ${ }^{26}$. However, stroke efficiency can not necessarily be taken as the sole indicator for successful skill learning. Movement form criteria are frequently attained 
independently of efficiency criteria ${ }^{27}$ : a learner may acquire a spatial or rhythm pattern of a skill without showing the mechanical or energetic efficiency, which is crucial for improving stroke index, for example due to a lack of muscular strength or endurance. So as secondary aim we studied the resemblance of the learner's spatial and rhythm patterns to those specified by manuals and displayed by elite swimmers, respectively. In order to assess possible relations between these indicators (spatial/ rhythmic form and efficiency) we furthermore calculated the correlations between stroke efficiency and both spatial and rhythmic pattern shown by participants throughout the test phases.

\section{Method}

\section{Participants}

Following approval of the procedure by the university's ethics committee, fifty university students ( 25 men and 25 women aged $21.2 \pm 3.84$ years) volunteered to participate in the study, declaring they possessed basic swimming skills but had no experience in breaststroke swimming ${ }^{a}$. To reassure this declared information, all participants who performed noticeably better than a typical novice to the breaststroke kick during the first test trials, were eliminated from the sample. After signing informed consent forms, participants were distributed evenly into four experimental groups, based on their average speed in a $15 \mathrm{~m}$ freestyle swimming test.

\section{Task}

All participants performed the breaststroke kick in prone position in 400 acquisition trials on two days, with a 48 hour interval between them. Acquisition trial series were divided into four blocks of five trial sets (4 blocks of 5 sets of 10 kicks) each day, the first and last of which were later analysed (labelled A1, A2 for the first day and A3, A4 for the second day). A retention test and a transfer test, both consisting of five sets of ten kicks, were performed another 48 hours later, the latter in supine position. During all trials participants used a floating tube ("pool noodle") to keep their shoulders at water level, passing it under their armpits, holding one end in each hand. In order to stabilize the horizontal float before starting, a pull-buoy was placed between their thighs which was released with the first kick.

\section{Setting}

Data were collected in a $25 \mathrm{~m}$ heated indoor pool $\left(29^{\circ} \mathrm{C}\right)$ between $0.90 \mathrm{~m}$ and $1.50 \mathrm{~m}$ deep, with a purpose built reference system consisting of coloured lane ropes as shown in FIGURE 1.

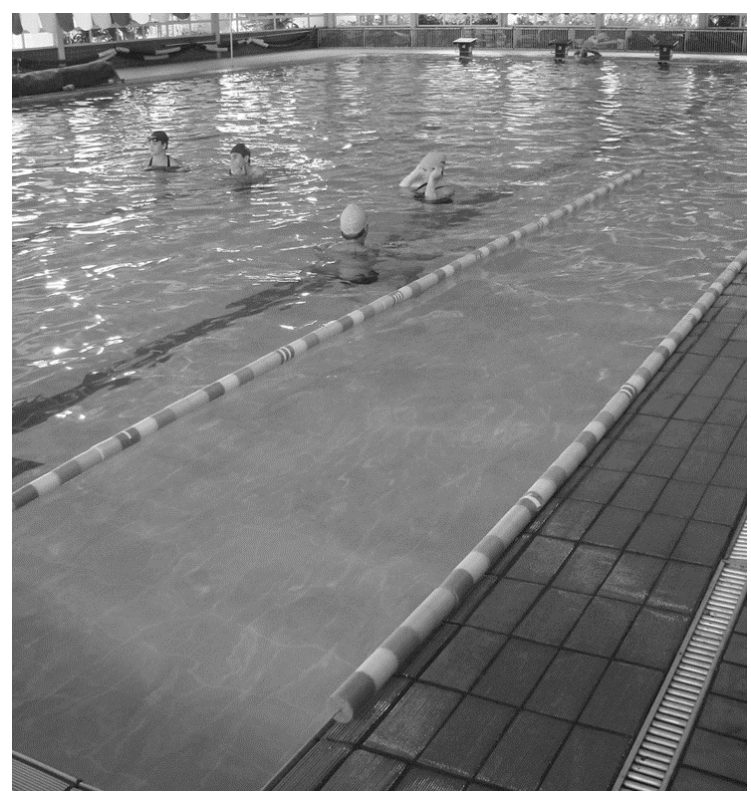

FIGURE 1 - Data collection setting with purpose built reference system 


\section{Stimuli}

Each of the four experimental groups was provided with a group specific instruction created specifically for this study: visual $(\mathrm{V})$ or auditory $(\mathrm{A})$, containing or not the adequate rhythmic pattern information (with $-C$, without $-S$ ), created specifically for this study. The visual instruction consisted of a video showing a skilled model performing the breaststroke kick. For the VS version, the original video recording of the kick was edited, stretching or compressing the duration of each phase so that the feet appeared to move at a uniform speed throughout all phases, and to show no gliding phase. The foot's trajectory was emphasized with a yellow arrow. For the VC version, the duration of each phase was adjusted to reflect the average phase duration shown by three elite swimmers ${ }^{28,29}$, including foot acceleration during insweep phase. The acceleration was emphasised by changing the arrow's colour to red during this phase, as shown in FIGURE 2.

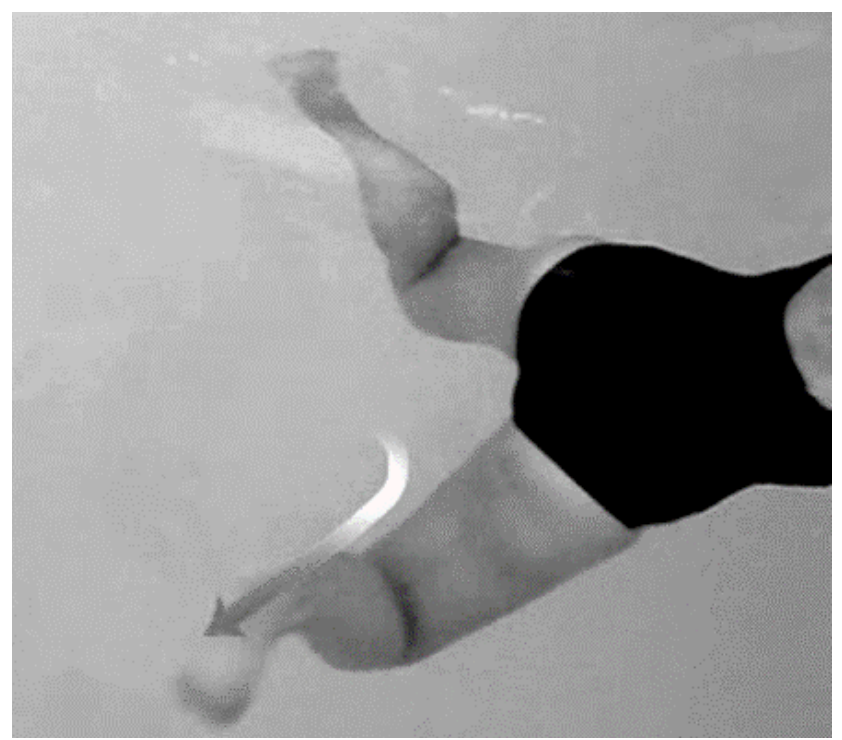

FIGURE 2 - Screenshot of VC stimulus during insweep phase showing colour change of the arrow emphasizing the foot acceleration

The auditory instruction consisted of an audio recording of a female voice saying "pull, open, kick, close" (in Portuguese), with constant speed and without stressing any syllable in the AS version, and accelerating speech speed during the "open, kick" phase, emphasising the "kick" syllable and adding a pause for the gliding phase between "close" and "pull" for the AC version. All four stimuli had equal length.

In summary, the rhythmic structure was emphasized in two ways both in the auditory and visual stimulus: firstly, by varying the duration of movement phases, and secondly by stressing acceleration phases. In the auditory stimulus the stress was expressed through speech melody and in the visual stimulus by colour change of the arrow indicating movement direction.

\section{Procedure}

On the first day, body mass and height were taken. Before starting each set of ten successive kicks (considering each kick as one trial) during acquisition phase, the participants could request their group specific instruction for as many times as they wanted ${ }^{30}$, or refuse a display of the instruction for that particular set of trials. No feedback was given. During retention and transfer tests, neither instruction nor feedback was provided. Each request was registered, including the number of the trial set it preceded. Occasionally participants would perform slightly less or more than ten kicks per set of trials, in this case the number of kicks was adjusted in subsequent sets of trials in order to keep an equal number of kicks per block. No feedback was given, and knowledge of results 
was restricted to the participant's casual observation of how far they got in each set of ten trials.

All trials were videotaped (Camera: Canon CyberShot DSC-H5), following the participant at approximately $1,5 \mathrm{~m}$ above water surface. The camera settings were adjusted to capture the participant's whole body as well as both lane ropes at all times.

After the data were collected, all trials of the first and the last acquisition block (A1, A2) on day 1 , and on day 2 (A3, A4) as well as all retention (RT) and transfer trials (TR) were analysed using Kinovea ${ }^{31}$ video analysis software (www.kinovea.org) in order to assess the dependent variables in all five trials of both the first and the last block on each of the two acquisition days, as well as all retention and transfer trials:

1) Mean value of stroke index (SI): speed times distance per stroke ${ }^{26}$. The speed was measured from the beginning of the second kick to the beginning of the last kick in each set of kick trials (usually 10). The distance per stroke is the displacement per set of kicks, excluding the first and the last, and divided by the number of kicks counted (usually eight).

2) Mean value of the rhythm pattern index (RPI) calculated from the participant's rhythm pattern in each kick between the second and the penultimate. The ideal pattern against which each of these kicks was measured had been established based on the analysis of videos showing the breaststroke performed by three elite swimmers ${ }^{28,29}$. This analysis yielded the following coincident typical rhythm pattern indicators: 1 . Pause between end of leg adduction and knee flexion, 2. Flexion phase shows less acceleration than abduction/adduction/extension phase;

3) Adduction and extension phase shows increasing and/or maximum acceleration. For each kick, conformity of these indicators with the ideal pattern would yield score 1.00 , and nonconformity would score .00 . So, within a set of kicks, conformity in some, but not in all kicks, would yield a partial score between .00 and 1.00 .

4) Mean value of the spatial pattern index (SPI) calculated from presence or absence of body part displacements according to stroke techniques as described by swimming manuals ${ }^{22-24}$, in a way similar to rhythm pattern index computing. The full presence of the following parameters would yield score 1.00 , whereas their partial presence would yield partial score: 1 . knees flex simultaneously and symmetrically, 2 . feet abduct simultaneously and symmetrically, 3 . knees extend simultaneously and symmetrically, 4 . feet adduct simultaneously and symmetrically.

All videos were rated by the same researcher, for whom the intra-rater reliability was $99,8 \%$. Both rhythm and spatial indices were calculated in percentage and expressed as indices ranging from .00 to 1.00 , with 1.00 standing for $100 \%$ of features present and .00 for none of the features present.

As an additional variable, the frequency of instruction requests at each set of ten trials was recorded.

\section{Statistical analysis}

Outcome scores (SI, RPI, and SPI) and instruction request frequency were subjected to descriptive and two-way analysis of variance having two levels of instruction stimulus (auditory, visual) and two levels of content regarding rhythmic structure (containing or not the adequate movement rhythm). Pearson's correlation coefficient $(r)$ was calculated to determine the relationship among outcome variables (stroke index, spatial and rhythm pattern indices).

\section{Results}

All participants were similar in terms of body mass, height and outcome in the first trial block (body mass: $\mathrm{F}(3,46)=.457 ; \mathrm{p}=.714$; height $\mathrm{F}(3,46)=.091$, $\mathrm{p}=.965$; stroke index: $\mathrm{F}(3,46)=.551 ; \mathrm{p}=.650$; spatial pattern index: $\mathrm{F}(3,46)=.968 ; \mathrm{p}=.416$; rhythmic pattern index: $\mathrm{F}(3,46)=.209$; $\mathrm{p}=.890)$.
The stroke index over the course of the acquisition blocks (A1 to A4) and retention (RT) and transfer block (TR) in all four groups yielded an $F$ ratio of $F(5,46)=28.952 ; \mathrm{p}<.001$, indicating that the participants increased their mean stroke index along acquisition trials $(F(3,105)=28.714 ; \mathrm{p}<.001$ 
for acquisition blocks A1 to A4), kept their stroke index between the last acquisition block and retention $(\mathrm{F}(1,35)=.025 ; \mathrm{p}=.875)$ but fell back to the initial index from retention to transfer test $(\mathrm{F}(1,35)=34.467 ; \mathrm{p}<.001)$ (TABLE 1$)$. The main effect of the stimulus did not prove significant $(F(3,46)=.005, p=.945)$ neither in the last acquisition block nor in retention or transfer blocks. However, the two groups that received information about rhythmic feature (AC/VC) showed distinct curve behaviour compared to the two groups who did not receive this information (AS/VS) in the retention block $\left(.145 \mathrm{~m}^{2} / \mathrm{s}\right.$ against $.094 \mathrm{~m}^{2} / \mathrm{s}$; $\mathrm{F}(1,46)=3.323 ; \mathrm{p}=.075)$, as shown in FIGURE 3 .

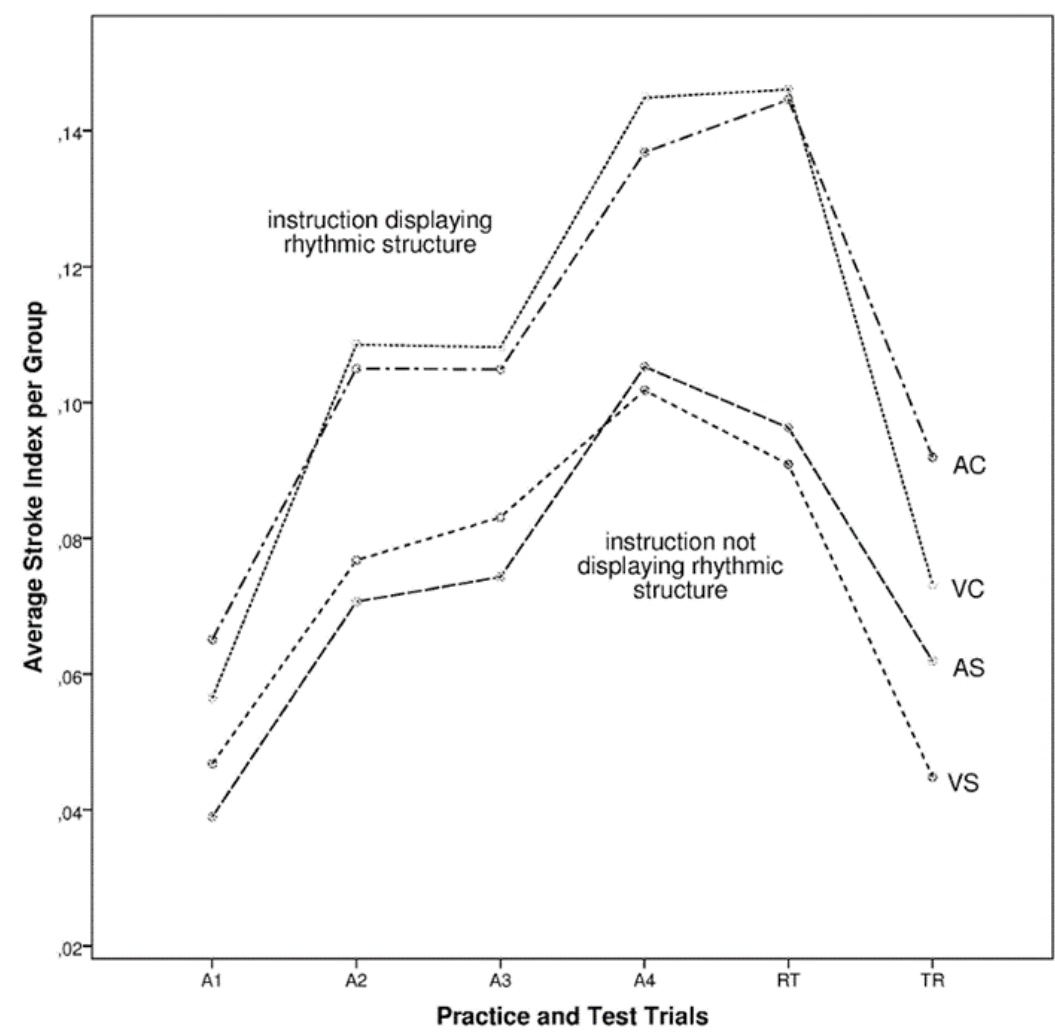

FIGURE 3 - Average stroke indices by groups over practice and testing trials

This difference in retention test almost attained the $\mathrm{p}<.05$ significance level typically accepted in motor learning research: $F(3,46)=3.323, p=.075$. Its effect can be considered of medium practical relevance $(r=0.285)^{32,33}$. The interaction of stimulus and rhythm was non-significant $(\mathrm{F}(3,46)=.015, \mathrm{p}=.904)$.

The spatial pattern index between all four groups over acquisition blocks yielded an $\mathrm{F}$ ratio of $\mathrm{F}(3,105)=4.381$; $\mathrm{p}=.014$, indicating that all participants did increase their spatial pattern index along acquisition phase. From the last acquisition trial to retention the index was $\operatorname{kept}(\mathrm{F}(1$, $35)=.866 ; \mathrm{p}=.358)$ and from retention to transfer too $(\mathrm{F}(1,35)=.107 ; \mathrm{p}=.746)$ (TABLE 2$)$. The main effect of stimulus did not prove significant $(\mathrm{F}(3,46)=2.027$, $\mathrm{p}=.161$ ), neither did the information about rhythmic structure $(\mathrm{F}(3,46)=2.565, \mathrm{p}=.116)$ nor the interaction effect $(\mathrm{F}(3,46)=1.709, \mathrm{p}=.198)$.
The rhythmic pattern index between all four groups over acquisition trial blocks yielded an $\mathrm{F}$ ratio of $\mathrm{F}(3,105)=1.911 ; \mathrm{p}=.146$, indicating that participants did not increase their spatial pattern index along acquisition phase. From the last acquisition trial to retention the index was kept $(\mathrm{F}(1,35)=1.552 ; \mathrm{p}=.221)$ as well as between retention and transfer test $(\mathrm{F}(1,35)=1.802$; $\mathrm{p}=.188$ ) (TABLE 3). Neither the main effect of stimulus nor the information about rhythmic structure did prove significant $(\mathrm{F}(3,46)=.685$ $\mathrm{p}=.570 ; \mathrm{F}(3,46)=.691, \mathrm{p}=.566)$. The interaction effect was non-significant $(\mathrm{F}(3,46)=1.434, \mathrm{p}=.234)$.

TABLE 4 shows mean and total instruction request frequency (IRF), whose overall means did not vary significantly $(\mathrm{F}(3,44)=.566 ; \mathrm{p}=.640)$ between groups during acquisition trials. 
TABLE 1 - Stroke index by group over trial blocks: A1 to A4 (acquisition), RT (retention) and TR (transfer).

\begin{tabular}{|c|c|c|c|c|c|c|c|c|c|c|}
\hline \multirow{2}{*}{ Variable } & \multicolumn{2}{|c|}{$\mathrm{N}=50$} & \multicolumn{2}{|c|}{$\mathrm{AC}$} & \multicolumn{2}{|c|}{ AS } & \multicolumn{2}{|c|}{ VC } & \multicolumn{2}{|c|}{ VS } \\
\hline & Mean & SD & Mean & SD & Mean & SD & Mean & SD & Mean & SD \\
\hline SI A1 & .052 & .053 & .065 & .065 & .039 & .034 & .057 & .060 & .047 & .051 \\
\hline SI A2 & .091 & .079 & .105 & .087 & .071 & .053 & .109 & .097 & .077 & .079 \\
\hline SI A3 & .093 & .087 & .105 & .087 & .074 & .069 & .108 & .105 & .083 & .087 \\
\hline SI A4 & .123 & .010 & .137 & .114 & .105 & .088 & .145 & .111 & .102 & .082 \\
\hline SI RT & .121 & .101 & .145 & .105 & .096 & .081 & .146 & .123 & .091 & .086 \\
\hline SI TR & .069 & .081 & .092 & .085 & .062 & .091 & .073 & .094 & .045 & .044 \\
\hline
\end{tabular}

TABLE 2 - Spatial pattern index by group over trial blocks: A1 to A4 (acquisition), RT (retention) and TR (transfer). Indices of 1.00 indicates presence of all spatial features according to technique description in current swimming technique manuals.

\begin{tabular}{|c|c|c|c|c|c|c|c|c|c|c|}
\hline \multirow{2}{*}{ Variable } & \multicolumn{2}{|c|}{$\mathrm{N}=50$} & \multicolumn{2}{|c|}{ AC } & \multicolumn{2}{|c|}{ AS } & \multicolumn{2}{|c|}{ VC } & \multicolumn{2}{|c|}{ VS } \\
\hline & Mean & SD & Mean & SD & Mean & SD & Mean & SD & Mean & SD \\
\hline SPI A1 & .832 & .292 & .849 & .262 & .723 & .362 & .833 & .358 & .924 & .102 \\
\hline SPI A2 & .937 & .180 & .961 & .078 & .835 & .295 & .950 & .174 & 997 & .008 \\
\hline SPI A3 & .924 & .201 & .939 & .118 & .845 & .340 & .956 & .953 & .953 & .108 \\
\hline SPI A4 & .940 & .192 & .935 & .208 & .876 & .295 & .991 & .033 & .957 & .144 \\
\hline SPI RT & .940 & .217 & 1.000 & $<.0001$ & .850 & .339 & .992 & .019 & .910 & .279 \\
\hline SPI TR & .931 & .234 & 1.000 & $<.0001$ & .824 & .373 & 991 & .033 & .898 & .284 \\
\hline
\end{tabular}

TABLE 3 - Rhythm pattern index by group over trial blocks: A1 to A4 (acquisition), RT (retention) and TR (transfer). Indices of 1.00 indicate presence of all rhythmic features as mapped in elite swimmers.

\begin{tabular}{|c|c|c|c|c|c|c|c|c|c|c|}
\hline \multirow{2}{*}{ Variable } & \multicolumn{2}{|c|}{$\mathrm{N}=50$} & \multicolumn{2}{|c|}{ AC } & \multicolumn{2}{|c|}{ AS } & \multicolumn{2}{|c|}{ VC } & \multicolumn{2}{|c|}{ VS } \\
\hline & Mean & SD & Mean & SD & Mean & SD & Mean & SD & Mean & SD \\
\hline RPI A1 & .510 & .426 & .530 & .423 & .470 & .441 & .575 & .401 & .453 & .481 \\
\hline RPI A2 & .536 & .464 & .691 & .479 & .495 & .420 & .374 & .447 & .587 & .503 \\
\hline RPI A3 & .555 & .454 & .720 & .413 & .523 & .447 & .416 & .469 & .559 & .485 \\
\hline RPI A4 & .626 & .462 & .729 & .417 & .636 & .445 & .539 & .519 & .600 & .497 \\
\hline RPI RT & .604 & .472 & .712 & .455 & .643 & .453 & .531 & .512 & .529 & .496 \\
\hline RPI TR & .536 & .454 & .710 & .429 & .504 & .510 & .515 & .408 & .402 & .469 \\
\hline
\end{tabular}


Ried B, et al.

TABLE 4 - Frequency of instruction request by groups and acquisition trial blocks, total amount of requests on the first and second day of trials and overall total.

\begin{tabular}{|c|c|c|c|c|c|c|c|c|c|c|}
\hline \multirow[t]{2}{*}{ Variable } & \multicolumn{2}{|c|}{$\mathrm{N}=50$} & \multicolumn{2}{|c|}{$\mathrm{AC}$} & \multicolumn{2}{|c|}{ AS } & \multicolumn{2}{|c|}{ VC } & \multicolumn{2}{|c|}{ VS } \\
\hline & Mean & SD & Mean & SD & Mean & SD & Mean & SD & Mean & SD \\
\hline IRF A1 & 4.80 & .272 & 4.77 & 2.2 & 4.55 & 2.7 & 4.54 & 2.85 & 5.41 & 3.37 \\
\hline IRF A2 & .80 & 1.32 & .62 & 1.19 & .96 & 1.56 & .46 & .88 & 1.27 & 1.62 \\
\hline IRF total day 1 & 7.28 & 5.59 & 7.00 & 5.43 & 7.05 & 5.17 & 7.73 & 6.44 & 7.32 & 5.88 \\
\hline IRF A3 & 2.62 & 2.41 & 1.84 & 1.23 & 2.55 & 2.12 & 3.08 & 3.51 & 3.00 & 2.67 \\
\hline IRF A4 & .41 & .99 & .31 & 1.11 & .5 & 1.25 & .54 & .97 & .27 & .65 \\
\hline IRF total day 2 & 4.67 & 3.97 & 3.58 & 4.42 & 5.36 & 5.43 & 4.04 & 2.63 & 6.00 & 2.91 \\
\hline IRF total overall & 12.68 & 6.84 & 11.42 & 8.19 & 13.32 & 6.25 & 11.69 & 6.5 & 14.68 & 6.47 \\
\hline
\end{tabular}

For the whole sample, correlations over all trial blocks were very high $(\mathrm{p}<.01)$ between stroke index and rhythmic pattern index, high $(\mathrm{p}<.05)$ between rhythmic pattern index and spatial pattern index except in the third acquisition block, but no correlation was found between stroke index and spatial pattern index (TABLES 5, 6, 7). Between some groups, stroke index and rhythmic pattern index correlations $(\mathrm{p}<.05)$ were found in some trial blocks, but without showing any clear pattern. *correlation is significant at .05 (two-tailed)

${ }^{* *}$ correlation is significant at .01 (two-tailed)

*correlation is significant at .05 (two-tailed) $r$ values were not obtained due to constant spatial pattern index values in AS group in RT and TR trials
TABLE 5 - Correlation (Pearson's $r$ ) between stroke index and rhythm pattern index of groups along trial blocks.

\begin{tabular}{|c|c|c|c|c|c|c|c|c|c|c|}
\hline & \multicolumn{2}{|c|}{$\mathrm{N}=50$} & \multicolumn{2}{|c|}{ AC } & \multicolumn{2}{|c|}{ AS } & \multicolumn{2}{|c|}{ VC } & \multicolumn{2}{|c|}{ VS } \\
\hline RPI x SI & $\mathbf{r}$ & $\mathbf{p}$ & $\mathbf{r}$ & $\mathbf{p}$ & $\mathbf{r}$ & $\mathbf{p}$ & $\mathbf{r}$ & $\mathbf{p}$ & $\mathbf{r}$ & $\mathbf{p}$ \\
\hline A1 & $.613^{* *}$ & $<.001$ & $.664^{*}$ & .013 & $.656^{*}$ & .021 & $.625^{*}$ & .042 & $.592^{*}$ & .042 \\
\hline A2 & $.493^{* *}$ & $<.001$ & .535 & .059 & .423 & .183 & $.664^{*}$ & .013 & .455 & .137 \\
\hline A3 & $.435^{* *}$ & .002 & .38 & .2 & .481 & .113 & .514 & .073 & .439 & .154 \\
\hline A4 & $.408^{* *}$ & .003 & .419 & .254 & .546 & .066 & .315 & .293 & .502 & .097 \\
\hline RT & $.413^{* *}$ & .003 & .451 & .122 & $.577^{*}$ & .049 & .237 & .435 & .57 & .053 \\
\hline TR & $.508^{* *}$ & $<.001$ & $.554^{*}$ & .05 & .383 & .219 & .482 & .095 & $.705^{*}$ & .01 \\
\hline
\end{tabular}

TABLE 6 - Correlation (Pearson's $r$ ) between stroke index and spatial pattern index of groups along trial blocks.

\begin{tabular}{|c|c|c|c|c|c|c|c|c|c|c|}
\hline & \multicolumn{2}{|c|}{$\mathrm{N}=50$} & \multicolumn{2}{|c|}{ AC } & \multicolumn{2}{|c|}{ AS } & \multicolumn{2}{|c|}{ VC } & \multicolumn{2}{|c|}{ VS } \\
\hline SPI $x$ SI & $\mathrm{r}$ & $\mathrm{p}$ & $r$ & $\mathrm{p}$ & $\mathrm{r}$ & $\mathrm{p}$ & $\mathrm{r}$ & $\mathrm{p}$ & $\mathrm{r}$ & $\mathrm{p}$ \\
\hline A1 & .248 & .083 & .293 & .332 & .421 & .173 & .152 & .32 & .337 & .284 \\
\hline A2 & .258 & .07 & .53 & .062 & .268 & .4 & .325 & .278 & .242 & .449 \\
\hline A3 & .233 & .104 & .448 & .125 & .114 & .724 & .311 & .302 & .282 & .374 \\
\hline A4 & .13 & .368 & -.007 & .982 & .198 & .536 & .396 & .18 & .2 & .534 \\
\hline RT & 199 & .165 & $(\mathrm{n} / \text { calc })^{1}$ & (n/calc) & .291 & .359 & .529 & .063 & .145 & .652 \\
\hline TR & .139 & .335 & (n/calc) & (n/calc) & .07 & .828 & .216 & .478 & .376 & .228 \\
\hline
\end{tabular}


TABLE 7 - Correlation (Pearson's $r$ ) between spatial pattern and rhythm pattern indices of groups along trial blocks.

\begin{tabular}{|c|c|c|c|c|c|c|c|c|c|c|}
\hline \multirow[b]{2}{*}{ SPI $x$ RPI } & \multicolumn{2}{|c|}{$\mathrm{N}=50$} & \multicolumn{2}{|c|}{$\mathrm{AC}$} & \multicolumn{2}{|c|}{ AS } & \multicolumn{2}{|c|}{ VC } & \multicolumn{2}{|c|}{ VS } \\
\hline & $\mathbf{r}$ & $\mathbf{p}$ & $\mathbf{r}$ & $\mathbf{p}$ & $\mathbf{r}$ & $\mathbf{p}$ & $\mathbf{r}$ & $\mathbf{p}$ & $\mathbf{r}$ & $\mathbf{p}$ \\
\hline A1 & $.325^{*}$ & .021 & .519 & .069 & $.652^{*}$ & .021 & -.055 & .858 & .441 & .151 \\
\hline A2 & $.350^{*}$ & .013 & $.790^{* *}$ & .001 & .52 & .083 & .256 & .398 & .503 & .095 \\
\hline A3 & .134 & .354 & .147 & .632 & -.024 & .942 & .266 & .379 & .53 & .076 \\
\hline A4 & $.379^{* *}$ & .007 & $.564^{*}$ & .045 & .528 & .078 & .312 & .3 & .396 & .202 \\
\hline RT & $.314^{*}$ & .026 & $(\mathrm{n} / \mathrm{calc} .)^{* * *}$ & (n/ calc.) & $.580^{*}$ & .048 & .07 & .82 & .376 & .229 \\
\hline TR & $.324^{*}$ & .022 & (n/ calc.) & (n/ calc.) & .477 & .117 & -.11 & .971 & .315 & .318 \\
\hline
\end{tabular}

\section{Discussion}

Although all participants increased their breaststroke kick efficiency and spatial pattern index, group analysis did not show statistically significant differences in any of the three dependent variables, if we take the alpha $\mathrm{p}<.05$ which is typically accepted in motor learning research. However, this threshold has been questioned in the last years for behavioural research $^{32,33}$, and marginally significant differences have been considered in motor learning research ${ }^{34}$. So, even if only marginally significant, the difference between instruction containing and not containing rhythm indicates an intriguing tendency that certainly deserves further attention. The higher stroke index $\left(.145 \mathrm{~m}^{2} / \mathrm{s}\right)$ obtained in the retention test by participants that received instruction containing information about adequate rhythmic pattern (AC/ $\mathrm{VC}$ ), against $.094 \mathrm{~m}^{2} / \mathrm{s}$ in participants who received instruction that did not contain this information (AS/VS) together with its medium size effect for practical relevance suggests that information about the rhythmic structure is somewhat relevant to learning an efficient breaststroke kick. Similar findings were reported by RiEder, BALSCHBACH, PAYER $^{35}$ for the tennis serve and ski slalom. Their experimental groups had performed rhythmic exercises prior to testing and showed better learning results than the control group that had performed equivalent, but not rhythm-focused exercises. WANG and $\mathrm{HART}^{36}$ compared butterfly stroke learning outcome between groups receiving or not additional auditory information (the sound of splashing water produced by an expert butterfly swimmer). Their experimental group performed significantly better both in quantitative and qualitative measures.

No difference was found between auditory and visual instruction. This shows that for our participants both stimuli conveyed comparable information, and that both pathways provided sufficient information for performing the skill. This deviates from previous findings as reported by Hodges and Franks ${ }^{3}$, who argue that visual instruction would lead to a better outcome in acquisition and retention trials than auditory instruction because for complex skills presented to beginners, visual instruction requires less attentional and processing resources than auditory instruction. Their thesis is corroborated by LaGuna ${ }^{1}$, who compared participants receiving either visual or verbal instruction, and found better cognitive representation in the visual than in the verbal instruction group. However, except Rieder, Balschbach, Payer ${ }^{35}$ and WANG and HART ${ }^{36}$, authors normally do not report whether their auditory instruction contained any information about rhythmic features. This lack of congruence in procedure may jeopardize comparison to other results of instructional research in motor learning.

Spatial pattern index came close to the ideal (index value 1.00) along acquisition trials and remained high in the retention test. On the other hand, no significant improvement was found for the rhythmic pattern index. Along all trials, participants showed high intragroup variation: the standard deviation was very close to the mean values, which may have masked emergence of inter-group differences. *correlation is significant at .05 (two-tailed) ${ }^{* *}$ correlation is significant at .01 (two-tailed) ${ }^{* * *} r$ values were not obtained due to constant spatial pattern index values in AS group in RT and TR trials 
The high correlation found between stroke index and rhythmic pattern index emphasises the close connection between efficiency in performing a motor skill and correctly executing its rhythmic structure. As MeInel and $\mathrm{SchNabel}^{7}$ point out, the maximum amplitude of a movement is not necessarily the best choice in all cases, but the amplitude and duration of the movement relate directly to the way in which the maximum of momentum can be transferred. This is especially true for swimming skills, in which efficiency depends essentially on the interaction of the swimmer with the water ${ }^{13}$. This may seem obvious, but has not been taken seriously into consideration in swimming teaching and training until the end of the last century ${ }^{37,38}$. In this interaction, the degree of temporal adjustment between the several motor actions that constitute a swimming skill, the reaction forces generated in water, and the following motor actions that pursue maximum utilisation of these reaction forces for propulsion, will result in higher efficiency of the stroke. In other words, the better this temporal adjustment, the higher the outcome ${ }^{16}$.

On the other hand, we did not find correlations between stroke index and spatial pattern index. In other words, our results indicate that a good spatial pattern not necessarily ensures stroke efficiency. This finding contradicts traditional swimming teaching practice, which focuses mainly on spatial features of a swimming skill. One should instead give priority to rhythmic features of the skill in order to improve stroke efficiency. These thoughts are in line with Schmidt and Wrisberg's ${ }^{6}$, and Meinel and Schnabel's ${ }^{7}$ position that a skill is qualified by its rhythmic structure which distinguishes one skill from another: its fluency, constancy, force and speed. Spatial features like amplitude and precision are essentially a consequence of rhythmic structure.

FRANK $^{38}$ remarks that a swimming skill whose rhythmic pattern is not adequate may result in a vicious cycle: an unfavourable relation between energy cost and outcome (applied force vs. propulsion generated) may compromise the production as well as the use of thrust bearings (portions of water of higher density), which compromises the alternation of force application and relaxation, and thereby results in an even poorer usage of the energy invested. This rationale is supported by SEIFERT and CHOLLET ${ }^{27}$ who concluded that, regarding arm pull and leg kick coordination in the breaststroke, the main difference between novice and expert breaststroke swimmers is the temporal relation between both skill components.

We did not find correlations between spatial pattern index and stroke index, but only between rhythmic pattern and stroke index. This difference in correlations might be due to different attentional and processing demands for neural processing of spatial and rhythmic perceptions. As pointed out by Ried, Rodrigues, Gama ${ }^{39}$ rhythm processing activates several different cerebral areas. KoffKA ${ }^{40}$ found that rhythmically organized events are not perceived individually, but as one whole, sole unit of information ${ }^{41}$. In other words, a sequence of rhythmically organized events, including its intervals, is taken as one single information unit. On the other hand, recognizing spatial patterns requires the viewer to identify both moving and stationary segments as well as the directions, angles and distances of their movement in relation to a reference system ${ }^{42,43}$. This demands more neural processing resources than the processing of a single unit of information comprising a set of rhythmically structured events.

Brain mapping studies found that perception of rhythm activates not only perception areas, but also adjacent motor areas ${ }^{44-48}$, reinforcing the tight relation between perception and action in rhythmic structures. Although this coupling was also found between spatial perception and action ${ }^{8}$, the higher resource requirements of spatial perception may contribute to a lower impact on stroke efficiency. This presumed interaction may be part of the reason why we found the stroke index to be correlated with the rhythmic pattern index, but not with the spatial pattern index.

This study aimed to clarify how different forms of instruction influence the learning of the breaststroke kick; specifically the effect of presenting the typical rhythmic pattern of the skill as opposed to a distorted version, as well as the difference between auditory and visual presentation. Considering our initial hypothesis, the results demonstrate that instructions respecting the adequate rhythmic structure did manifest in different ways in the learning process. In conclusion, our findings indicate that focusing on or emphasizing movement rhythm when teaching complex motor skills, be it by demonstration or by auditory instruction, can improve the learning outcomes for skills like the breaststroke kick, especially regarding stroke efficiency. In sports education settings, our findings may contribute to increase the efficiency of teaching 
complex motor skills like the breaststroke kick by emphasising those features that are most strongly related to and critical for performance efficiency.
This is especially relevant in teaching novices since it will allow teachers to help them to develop efficiency in propulsion more easily.

\section{Resumo}

Instrução contendo a estrutura rítmica da habilidade melhora a eficiência na aprendizagem da pernada do nado peito

A aprendizagem de habilidades motoras pode ser promovida mediante instrução visual ou auditiva que transmite informações sobre diversas características da habilidade, tais como espaciais ou rítmicas. Para habilidades aquáticas como a pernada do nado peito, os manuais técnicos enfatizam características espaciais, negligenciando aspectos rítmicos da habilidade, apesar de a teoria da aprendizagem motora considerar 0 timing relativo uma característica crucial na distinção entre uma habilidade e outra. Objetivou-se analisar o impacto da instrução com e sem a informação sobre a estrutura rítmica correta, transmitida visual ou auditivamente, sobre a aprendizagem da pernada do nado peito. Cinquenta estudantes de Educação Física foram distribuídos em quatro grupos experimentais (instrução auditiva, visual, com e sem informação rítmica correta) e realizaram 400 tentativas de aquisição da pernada do nado peito, mais 50 de retenção e 50 de transferência, durante as quais foram mapeados os índices de pernada, de configuração rítmica e espacial. Os resultados mostraram índices marginalmente melhores $(p=0,075)$, no teste de retenção, dos participantes que receberam a instrução com a informação rítmica correta, e uma forte correlação entre os índices de pernada com os de configuração rítmica ao longo de todo o processo, mas não com os de configuração espacial. Não houve diferença entre os grupos de instrução visual e auditiva. Esses resultados corroboram resultados anteriores sobre os efeitos da informação rítmica na aprendizagem de uma habilidade motora complexa, e reforçam o papel do ritmo na eficiência na execução de uma habilidade e consequentemente na sua aprendizagem.

PalAVRAS-CHAVE: Instrução; Desempenho; Aprendizagem motora; Natação; Nado peito.

\section{Notes}

${ }^{a}$ For this purpose, participants were presented drawings showing the breaststroke phases ${ }^{22}$.

\section{References}

1. Laguna P. Task complexity and sources of task-related information during the observational learning process. J Sports Sci. 2008;26(10):1097-113.

2. Hodges NJ, Williams AM, Hayes SJ, Breslin G. What is modelled during observational learning? J Sports Sci. 2007;25:531-45.

3. Hodges N, Franks I. Instructions, demonstrations and the learning process. In: Williams M, Hodges F, editors. Skill acquisition in sport: research, theory \& practice. New York: Routledge; 2004. p. 145-174.

4. Tani G, Bruzi AT, Bastos FH, Chiviakowsky S. O estudo da demonstração em aprendizagem motora: estado da arte, desafios e perspectivas. Rev Bras Cineantropom Desempenho Hum. 2011;13(5):392-403.

5. Künzell S. Optimal attentional focus in practical sport settings: always external or task specific? Bewegung und Training [Internet]. 2007 [cited 2019 Feb 28];1:27-8. Available from: http://bit.ly/2tGmdsb.

6. Schmidt RA, Wrisberg CA. Aprendizagem e performance motora. Porto Alegre: Artmed; 2011.

7. Meinel K, Schnabel G. Bewegungslehre Sportmotorik. Aachen: Meyer \& Meyer; 2007. 
8. Vogt S, Tomaschke R. From visuo-motor interactions to imitation learning: behavioural and brain imaging studies. J Sports Sci. 2007;25(5):497-517.

9. Tani G, Corrêa UC, Basso L, Benda RN, Ugrinowitsch H, Choshi K. An adaptive process model of motor learning: insights for the teaching of motor skills. Nonlinear Dynamics Psychol Life Sci. 2014;18(1):47-65.

10. Brochard R, Touzalin P, Després O, Dufour A. Evidence of beat perception via purely tactile stimulation. Brain Res. 2008;1223:59-64.

11. Grahn J, Henry M, Mcauley J. FMRI investigation of cross-modal interactions in beat perception: audition primes vision, but not vice versa. Neuroimage. 2011;54:1231-43.

12. Thaut M. Rhythm, music and the brain. New York: Routledge; 2005. p. 4.

13. Ungerechts B, Persyn U, Colman V. Analysis of swimming techniques using vortex traces [Internet]. In: Proceedings of the 18th International Symposium on Biomechanics in Sports; 2000 Jun 25-30; Hong Kong, China. Konstanz: ISBS; 2000. p.104-112. Available from: http://bit.ly/2EjhFwR.

14. Triantafyllou MS, Triantafyllou GS, Yue DKP. Hydrodynamics of fishlike swimming. Annu Rev Fluid Mech. 2000;32:33-53.

15. Takagi H, Sugimoto S, Nishijima N, Wilson B. Swimming: differences in stroke phases, arm-leg coordination and velocity fluctuation due to event, gender and performance level in breaststroke. Sports Biomech. 2004;3(1):15-27.

16. Seifert L, Chollet D. A new index of flat breaststroke propulsion: a comparison of elite men and women. J Sports Sci. 2005;23(3):309-20.

17. Makarenko LP. Natação. Porto Alegre: Artmed; 2001.

18. Lewin K. Schwimmsport. Berlin: Sportverlag; 1974.

19. Counsilman JE. Schwimmen. Bad Homburg: Limpert; 1978.

20. Reischle K. Biomechanik des Schwimmens. Bockenem: Fahnemann; 1988.

21. Maglischo E. Nadar mais rápido. Barueri: Manole; 1999.

22. Colwin C. Nadando para o século XXI. Barueri: Manole; 2000.

23. Ungerechts B, Volck G, Freitag W. Lehrplan Schwimmsport. Schorndorf: Hofmann; 2002.

24. Bissig M, Gröbli C, Amos L, Cserepy S. Schwimmwelt: Schwimmen lernen, Schwimmtechnik optimieren. Bern: Schulverlag; 2004.

25. Wilke K. Schwimmen lernen fuer Kinder und Erwachsene. Aachen: Meyer \& Meyer; 2007.

26. Sanchez J, Arellano R. Stroke index values according to level, gender, swimming style and event race distance [Internet]. In: Gianikellis K, editor. Proceedings of the XXth International Symposium on Biomechanics in Sports [Internet]. Cáceres: Universidad de Extremadura; 2002 [cited 2019 Feb 28]. p. 56-9. Available from: http://bit.ly/2TkYpsb.

27. Seifert L, Chollet D. Inter-limb coordination and constraints in swimming: a review. In: Beaulieu NP, editor. Physical activity and children: new research. New York: Nova Science; 2008. p. 65-93.

28. Soni R. Rebecca Soni: Adding a second kick to your breaststroke [video]. San Bruno: YouTube; 2012 [cited 2019 Feb 28]. Available from: http://bit.ly/2Svopg1.

29. Weber PA, Schumacher D, Battanta P. Swimworld basic 2 [DVD]. Magglingen: Bundesamt fuer Sport; 1999.

30. Sanli EA, Patterson JT, Bray SR, LeeTD. Understanding self-controlled motor learning protocols through the self-determination theory. Front Psychol. 2012;3:611.

31. Apolinário MR, Oliveira TAC, Ferreira LF, Basso L, Corrêa UC, Freudenheim AM. Efeitos de diferentes padróes respiratórios no desempenho e na organização temporal das braçadas do nado "Crawl”. Rev Bras Educ Fís Esporte 2012;26(1):149-59.

32. Ellis PD. The essential guide to effect sizes. Cambridge: University Press; 2010.

33. Nuzzo R. Scientific method: statistical errors. Nature. 2014,506:150-2.

34. Wulf G, Chiviacowsky S, Schiller E, Ávila LTG. Frequent external-focus feedback enhances motor learning. Front Psychol. 2010;1:190. doi: 10.3389/fpsyg.2010.00190.

35. Rieder H, Balschbach R, Payer B. Lernen durch Rhythmus. Köln: Sport und Buch Strauss; 1991.

36. Wang L, Hart M. Influence of auditory modeling on the learning of a swimming skill. Percept Mot Skills. 2005;100:640-8.

37. Langendorfer SJ, Bruya LD. Aquatic readiness. Champaign: Human Kinetics; 1995.

38. Frank G. Koordinative Fähigkeiten im Schwimmen. Schorndorf: Hofmann; 2008.

39. Ried B, Rodrigues G, Gama EF. Rhythm and its perception in the central nervous system. J Morphol Sci. 2015;31(3):187-97.

40. Koffka K. Experimental-Untersuchungen zur Lehre vom Rhythmus. Leipzig: Barth; 1908.

41. Spitznagel A. Zur Geschichte der psychologischen Rhythmusforschung. In: Müller K, Aschersleben G, editors. Rhythmus. Ein interdisziplinäres Handbuch. Bern: Huber; 2000. p. 1-40.

42. Shelton AL, McNamara TP. Systems of spatial reference in human memory. Cogn Psychol. 2001;43(4):274-310. 
43. Lent R. Cem bilhões de neurônios? Conceitos fundamentais de neurociência. São Paulo: Atheneu; 2010.

44. Molinari M, Leggio MG, De Martin M, Cerasa A, Thaut M. Neurobiology of rhythmic motor entrainment. Ann N Y Acad Sci. 2003;999:313-21.

45. Limb CJ, Kemeny S, Ortigoza EB, Rouhani SL, Braun AR. Left hemispheric lateralization of brain activity during passive rhythm perception in musicians. Anat Rec A Discov Mole Cell Evol Biol. 2006;288(4):382-9.

46. Grahn JA, Brett M. Rhythm and beat perception in motor areas of the brain. J Cogn Neurosci. 2007;19(5):893-906.

47. Chen J, Penhune VB, Zatorre RJ. Listening to musical rhythms recruits motor regions of the brain. Cereb Cortex. 2008;18:2844-54.

48. Bengtsson SL, Ullen F, Ehrsson H, Hashimoto T, Kito T, Naito E et al. Listening to rhythms activates motor and premotor cortices. Cortex. 2009;45(1):62-71.

\begin{tabular}{r|r} 
ENDEREÇo & \\
Bettina Ried & \\
Escola Superior de Educação Física de Jundiaí & Submitted: 21/01/2015 \\
Rua Rodrigo Soares de Oliveira, s/n & Review: 16/09/2015 \\
Bairro Anhangabaú & Accepted: 03/04/2017 \\
13208-120 - Jundiaí - SP - BRASIL & \\
e-mail: bried@esef.br; bettina.ried@gmx.net & \\
&
\end{tabular}


